\title{
Studies on the Flight of Rhagoletis Cerasi L. Adults in Treated and Untreated Plantations in Cluj-Napoca Area
}

\author{
Laura Ioana MACAVEI ${ }^{1 *}$, Ion OLTEAN ${ }^{1}$, Teodora FLORIAN ${ }^{1}$, Viorel MITRE $^{2}$, \\ Ioan OPREAN ${ }^{3}$, Aurelia POP ${ }^{3}$, Iuliana VASIAN ${ }^{3}$ \\ ${ }^{1}$ Faculty of Agriculture. University of Agricultural Science and Veterinary medicine Cluj-Napoca, Cluj- \\ Napoca, no. 1-3 Calea Mănăștur Street, Romania; \\ ${ }^{2}$ Faculty of Horticulture. University of Agricultural Science and Veterinary medicine Cluj-Napoca \\ ${ }^{3}$ Institute for Research in Chemistry “Raluca Ripan”." Babes-Bolyai” University, Cluj-Napoca, 29-30 \\ Fântânele Street, 2004657 Cluj-Napoca, Romania; \\ * corresponding author: macavei_laura87@yahoo.com
}

Bulletin USAMV series Agriculture 72(1)/2015

Print ISSN 1843-5246; Electronic ISSN 1843-5386

DOI 10.15835/buasvmcn-agr: 10612

\begin{abstract}
Rhagoletis cerasi L. is the main pest of sweet cherry and sour cherry orchards, whose attack may decrease the quality of fruits in a high percentage. The experiment took place in two locations from Cluj-Napoca city. During 2 experimental years we observed the population

dynamics of European cherry fruit fly. In the year 2013 adults emergence took place on May 25. The maximum level of population was reached in June 10 in untreated orchard, respectively on the 24th of June in the case of chemically treated orchard. In 2014 the first captures were recorded on May 21 and the peak flight was achieved in untreated orchard on June 3 and June 17 in the orchard were chemical treatments where applied. The total flight period of adults ranged on an interval of 36-51 days in the year 2013 and 48-51 days in 2014.
\end{abstract}

Keywords: European cherry fruit fly, dynamics population, yellow traps, Rhageletis cerasi L.

\section{INTRODUCTION}

Rhagoletis cerasi L. is considered to be the main pest of sweet cherry and sour cherry plantations. The attack of this pest may diminish the harvest up to $60 \%$ (Perju and Serban, 1996).

European cherry fruit fly is a univoltine species thatoverwintersasapupae, afewcmunderground.In spring from pupal stage with pink eyes and up to the emergence of first adults are required 1416 days. The emergence of first adults usually is recorded in the second decade of May (Ozdem and Kilincer, (2005), depending on location and climatic characteristics of the year (Croitoru et al., 2014). The flight of flies ranges between 35-75 days (Kovanci and Kovanci, 1999b; Stamenkovic et al., 1996). After about two weeks from emergence, when fruits are at the stage of colour change, turning from green to yellow, copulation and ovipozition occur (Boller and Prokopy, 1976).

For protection of orchards against this pest it is recommended the application of at least two or three chemical treatments (Olszak and Maciesiak, 2004). Due to ecotoxicity produced by chemicals, European Union already restricted in Germany a range of insecticides used for controlling of this pest (Daniel, 2009). Further the concept of integrated pests management is the best solution in terms of technology and a first step towards realizing the concept of environmental protection 
or sustainability. It is also the only one that can help improve and maintain the health of our environment. To implement this concept it is required a high level of knowledge on bioecology of pest and as well about useful entomofauna from the area (Herea, 2011). Studies on the biology and population dynamics of Rhagoletis cerasi were conducted both in our country (Coneru, 2009; Chireceanu, 2008) and abroad (Stamenković, 2012; Kovanci and Kovanci, 2006a; Kovanci and Kovanci, 2006b).

The purpose of this paper is to study the dynamics population of European cherry fruit fly in plantations from Cluj-Napoca area, in order to apply a more reduced number of chemical treatments.

\section{MATERIALS AND METHODS}

The experiment took place during the years 2013 and 2014. Observations on adults flight dynamics were made in order to assess the population density of European cherry fruit fly. Research was carried out in 2 cherry plantations Cluj-Napoca city, Romania. The distance between the two plantations consisted in $50 \mathrm{~m}$. The technologies applied where different. Location 1 consisted in a plantation where no intervention through agrotechnical or chemical methods in controlling pests were made. Second location consisted in an orchard where chemical treatments were applied (including 2 treatments for controlling of European cherry fruit fly).

The monitoring of adults flight was made with the aid of yellow sticky panels (marked in the tables with M), yellow traps in which we added baits with different variants of attractant sexual pheromone (marked in the tables with F1, F2, F3, F4 and F5). In 2014 we added variants in which the pheromonal baits were placed on white sticky panels (marked in tables with V1, V2, V3, V4 and V5). The material used was provided by the Institute for Research in Chemistry "Raluca Ripan, Cluj-Napoca.

For data interpretation we used total number of catches recorded by all the types of traps. The functionality of pheromone formulations will be the theme of another publication.

In 2013 in May 20th a total number of 67 traps have been placed. 19 traps were installed in untreated orchard respectively 47 pieces in orchard where chemical treatments were applied. The traps were placed in order to cover the entire surface of each location. Removal of the experiment took place on July 4th in untreated orchard and on July 18 in the orchard where they applied chemical treatments.

In 2014, the number of traps placed in first location was 33 and the number of placed traps in chemically treated orchard was 55 pieces. Installation of the experiment this year took place in May 14. Monitoring activity ended in July 8 in untreated orchard respectively in July 10 in chemically treated orchard.

The traps were placed at an approximate height of 1,5-1, $8 \mathrm{~m}$, on the southern part of the canopy as Remund and Boller, (1983) sugested.

Observations on traps were made twice a week for both orchards, through counting of catches on each panel, and by difference we obtained the number of catches for each interval, between two successive observations. In order to compare the populations of the two locations we calculated the average number of captures / trap. In each orchard, at harvesting we examined the frequency of fruits damaged by Rhagoletis cerasi L.

\section{RESULTS AND DISCUSSION}

In 2013 the first flyes of species Rhagoletis cerasi L. emerged in the last decade of May for both monitored orchards. The last captured adults in untreated orchard were recorded on 1 July, and in chemical treated orchard in 15 July. The total number of adults captured was 430 individuals in first location and 1146 individuals in the second location.

Average number of catches recorded on a trap for the untreated orchard was 22.6 adults / trap (Tab. 1.) while in the chemically treated orchard we registered 23.9 adults / trap (Tab. 2.).

Although the average number of catches/ trap in chemically treated orchard is similar to the untreated orchard, while checking the frequency of attacked fruits we found a noticeable difference between the two locations. The frequency of attacked fruits registered in untreated plantation ranged between $37 \%$ and $46 \%$ (depending on variety). Due to chemical treatments, especially of the two treatments in the adult flight period, when it was used systemic insecticides, frequency 
of damaged fruits was very low (few fruits were attacked sporadically) allowing even export of a quantity of cherry harvest. Systemic insecticides certainly had effect on embryonic development of Rhagoletis cerasi.

The peak of Rhagoletis cerasi flight in untreated orchard, for the year 2013, is presented in (Fig. 1.).

The flight was distributed on a span of 36 days. The intensity of flight increased about a week after emergence (as of June 3). The maximum population was registered about two weeks after emergence. Between 7 and
10 June we registered 108 catches. From the presented data we can observe that between 3-20 June the number of captures was 391 adults, representing about $90 \%$ of the total catches.

In (Fig. 2.) we can observe the curve flight in chemically treated orchard. In this location the adults flight spread over a period of 51 days, period of flight similar as in Stamenkovic et al. (1996) research. Within this interval, from 10 June to 12 July were captured 1087 adults, representing $95 \%$ of total annual catches. The flight period is determined both by the biological reserve of species and the environmental conditions of the

Tab. 1. Number of captures registered in untreated orchard, 2013

\begin{tabular}{cccccccc}
\hline Date/Variant & $F 1$ & $F 2$ & $F 3$ & $F 4$ & $F 5$ & M & Total \\
\hline 25.05 & 0 & 0 & 0 & 0 & 1 & 2 & 3 \\
\hline 29.05 & 1 & 0 & 0 & 0 & 3 & 4 & 8 \\
\hline 3.06 & 1 & 2 & 1 & 0 & 9 & 10 & 23 \\
\hline 7.06 & 2 & 1 & 2 & 1 & 18 & 50 & 74 \\
\hline 10.06 & 18 & 15 & 15 & 10 & 14 & 36 & 108 \\
\hline 13.06 & 33 & 10 & 7 & 3 & 26 & 17 & 96 \\
\hline 17.06 & 16 & 6 & 3 & 3 & 6 & 10 & 44 \\
\hline 20.06 & 10 & 6 & 8 & 1 & 8 & 13 & 46 \\
\hline 24.06 & 5 & 2 & 1 & 0 & 4 & 3 & 15 \\
\hline 27.06 & 3 & 2 & 1 & 0 & 2 & 4 & 12 \\
\hline 1.07 & 1 & 0 & 0 & 0 & 0 & 0 & 1 \\
\hline 4.07 & 0 & 0 & 0 & 0 & 0 & 0 & 0 \\
\hline Total captures & 90 & 44 & 38 & 18 & 91 & 149 & 430 \\
\hline No. Traps & 2 & 2 & 2 & 2 & 5 & 6 & 19 \\
\hline Average/trap & 45 & 22 & 19 & 9 & 18.2 & 24.8 & 22,6 \\
\hline
\end{tabular}

Evolution of flight in untreated orchard, 2013

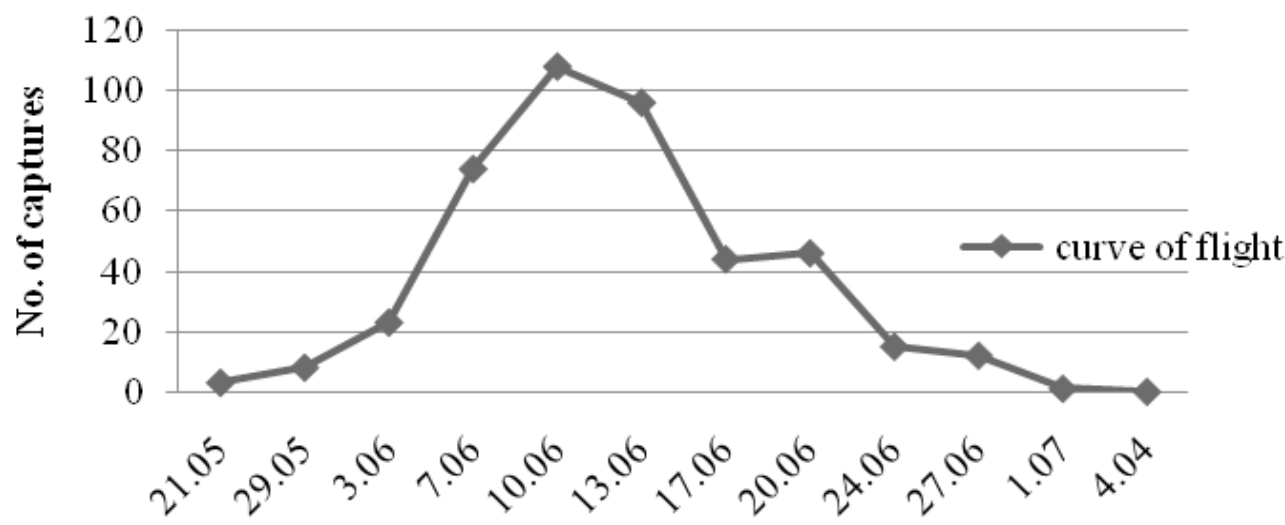

Dates of observations made in field

Fig. 1. Flight curve of Rhagoletis cerasi L. species in untreated orchard, Cluj, 2013 
area (Boller and Prokopy, 1976). In this plantation flight intensified after about two weeks, starting from June 7. In the orchard where chemical treatments where applied, the maximum flight curve was recorded after about a month. The number of adults captured between June 17 and June 20 was 214.

In the year 2014 the flight of Rhagoletis cerasi L. started on 21 May. Similar results were obtained in west side of Romania by Mincă (2011) and the southern part of Romania by Chireceanu (2008).

The total of specimens captured in untreated plantation was 434 individuals, with an average of 13.15 adults / trap (Tab. 3.). The level of captures on traps ranged between 3.6 and 28 adults / trap.

Comparing the average catches / trap between the two experimental years, it is noted that this year the average is lower by 11.45 captured adults

Tab.2. Number of captures registered in chemically treated orchard, 2013

\begin{tabular}{cccccccc}
\hline Date/Variant & F1 & F2 & F3 & F4 & F5 & M & Total \\
\hline 25.05 & 0 & 1 & 0 & 0 & 0 & 1 & 2 \\
\hline 29.05 & 1 & 0 & 0 & 0 & 0 & 4 & 5 \\
\hline 3.06 & 1 & 1 & 1 & 2 & 3 & 7 & 15 \\
\hline 7.06 & 3 & 0 & 3 & 2 & 3 & 10 & 21 \\
\hline 10.06 & 6 & 16 & 14 & 5 & 26 & 43 & 110 \\
\hline 13.06 & 17 & 12 & 4 & 8 & 31 & 24 & 96 \\
\hline 17.06 & 27 & 5 & 14 & 3 & 31 & 41 & 121 \\
\hline 20.06 & 14 & 6 & 3 & 5 & 40 & 56 & 124 \\
\hline 24.06 & 45 & 7 & 5 & 18 & 50 & 89 & 214 \\
\hline 27.06 & 12 & 0 & 6 & 2 & 33 & 30 & 83 \\
\hline 1.07 & 8 & 1 & 4 & 7 & 28 & 65 & 113 \\
\hline 4.07 & 5 & 1 & 10 & 3 & 40 & 27 & 86 \\
\hline 8.07 & 3 & 1 & 9 & 3 & 25 & 28 & 69 \\
\hline 12.07 & 5 & 4 & 9 & 1 & 26 & 26 & 71 \\
\hline 15.07 & 1 & 2 & 3 & 0 & 5 & 5 & 16 \\
\hline 18.07 & 0 & 0 & 0 & 0 & 0 & 0 & 0 \\
\hline Total captures & 148 & 57 & 85 & 59 & 341 & 456 & 1146 \\
\hline No. traps & 5 & 5 & 5 & 4 & 13 & 16 & 48 \\
\hline Average/trap & 19.6 & 11.4 & 17 & 14.75 & 26.23 & 28.5 & 23,9 \\
\hline
\end{tabular}

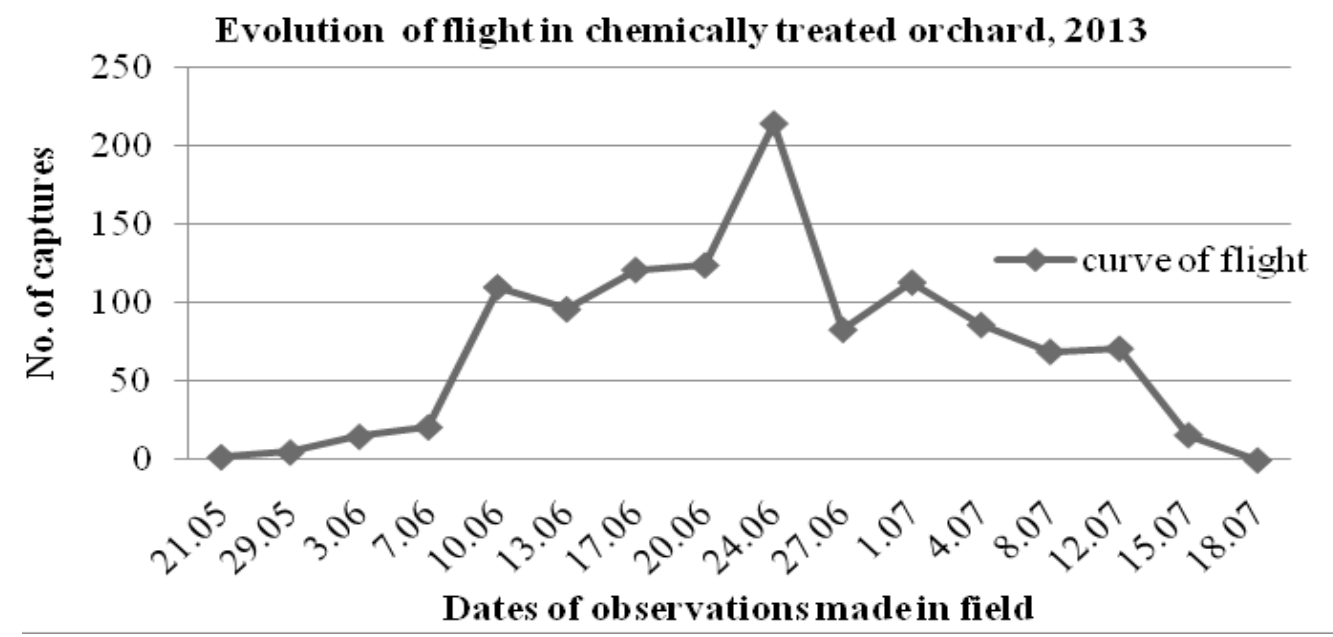

Fig. 2. Flight curve of Rhagoletis cerasi L. species in treated orchard, Cluj, 2013 
per trap from last year (a decrease of $41.8 \%$ ). It may be that the situation is determined by the heavy rains fell between 1 May- May 5 and also between May 14-May 18. In this period there were days with precipitation of $29.9 \mathrm{~mm}$ and excessive humidity. In the specialized literature it is mentioned that this type of wheader can induce a high rate of mortality to pupae development (Boller, 1966).

Flight curve of flight peak of Rhagoletis cerasi L. species in untreated orchard, in year 2014, is presented in (Fig. 3.). Adults flight period extended over a period of 48 days, with 12 days larger, compared to the year 2013. Maximum density of adults in untreated orchard was reached on June 3 when there were 118 specimens captured. It can be seen that during the period May 30 to July 17 were captured 376 adults, representing about $87 \%$ of the total catch.

In treated orchard as in the previous location, adults flight begun on May 21. During the second year of monitoring in the orchard where chemical treatments were applied, the total number of captured adults was 552 (Tab. 2.). In this location

Tab. 3. Number of captures registered in untreated orchard, 2014

\begin{tabular}{ccccccccccccc}
\hline Date/Variant & $\mathrm{F} 1$ & $\mathrm{~V} 1$ & $\mathrm{~F} 2$ & $\mathrm{~V} 2$ & $\mathrm{~F} 3$ & $\mathrm{~V} 3$ & $\mathrm{~F} 4$ & $\mathrm{~V} 4$ & $\mathrm{~F} 5$ & $\mathrm{~V} 5$ & $\mathrm{M}$ & Total \\
\hline 21.05 & 0 & 0 & 0 & 0 & 0 & 0 & 0 & 0 & 0 & 0 & 2 & 2 \\
\hline 30.05 & 1 & 2 & 14 & 0 & 5 & 2 & 2 & 3 & 8 & 2 & 12 & 51 \\
\hline 3.06 & 26 & 6 & 24 & 5 & 17 & 2 & 20 & 4 & 3 & 3 & 8 & 118 \\
\hline 6.06 & 2 & 4 & 14 & 4 & 12 & 3 & 17 & 0 & 5 & 1 & 10 & 72 \\
\hline 10.06 & 22 & 3 & 5 & 4 & 1 & 0 & 14 & 3 & 1 & 2 & 11 & 66 \\
\hline 13.06 & 15 & 0 & 7 & 2 & 3 & 2 & 5 & 0 & 2 & 2 & 6 & 44 \\
\hline 17.06 & 6 & 2 & 4 & 0 & 1 & 0 & 1 & 0 & 2 & 2 & 7 & 25 \\
\hline 20.06 & 3 & 2 & 2 & 0 & 0 & 0 & 0 & 0 & 0 & 0 & 1 & 8 \\
\hline 24.06 & 0 & 0 & 0 & 0 & 0 & 0 & 1 & 0 & 0 & 0 & 0 & 1 \\
\hline 27.06 & 6 & 1 & 4 & 0 & 2 & 1 & 2 & 0 & 5 & 1 & 3 & 25 \\
\hline 1.07 & 2 & 2 & 3 & 0 & 2 & 1 & 2 & 1 & 0 & 0 & 5 & 18 \\
\hline 4.07 & 1 & 0 & 0 & 1 & 0 & 0 & 1 & 0 & 0 & 0 & 1 & 4 \\
\hline 8.07 & 0 & 0 & 0 & 0 & 0 & 0 & 0 & 0 & 0 & 0 & 0 & 0 \\
\hline Total captures & 84 & 22 & 77 & 16 & 43 & 11 & 65 & 11 & 26 & 13 & 66 & 434 \\
\hline No. traps & 3 & 3 & 3 & 3 & 3 & 3 & 3 & 3 & 3 & 3 & 3 & 33 \\
\hline Average/trap & 28 & 7.3 & 25,6 & 5,3 & 14,3 & 3,6 & 21,66 & 3,6 & 8,6 & 4,3 & 22 & 13,15 \\
\hline
\end{tabular}

\section{Evolution of flight in untreated orchard, 2014}

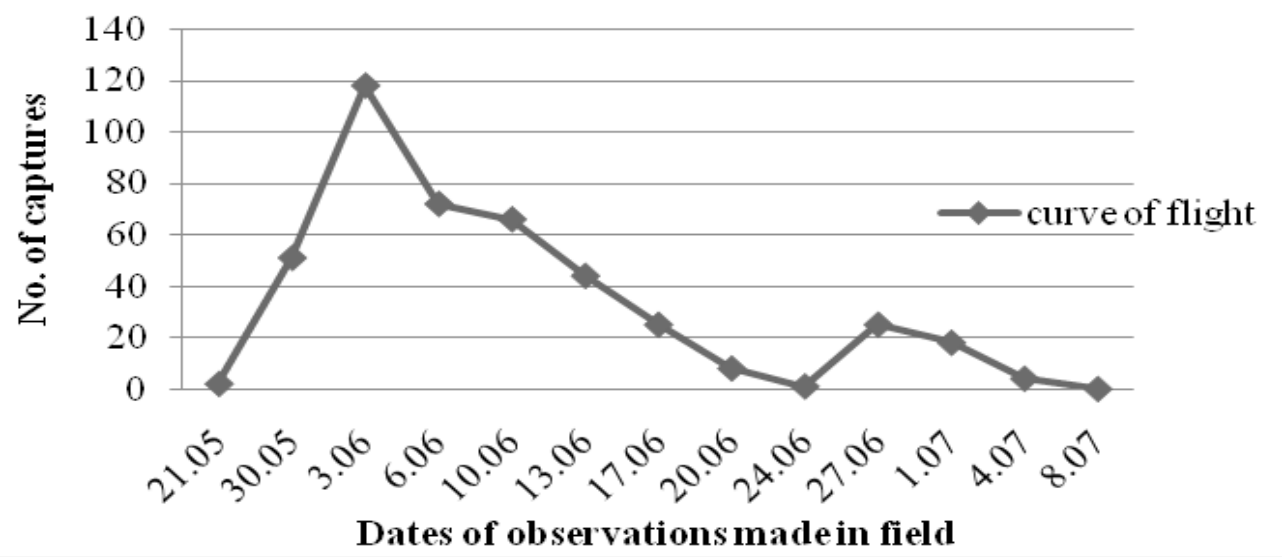

Fig. 3. Flight curve of Rhagoletis cerasi L. species in untreated orchard, Cluj, 2014 
the average number of catches was 10.03 adults / trap with 3.12 individuals fewer than in untreated orchard. A trap recorded between 2.8 and 25.8 adults / trap. Comparing the average catches from this year with the ones of last year, there was a decrease of 12.87 adults / trap (a decrease of 58.03\%). Population decrease compared to the previous year is due to chemical treatments performed and as we showed in last year frequency of attacked fruit was insignificant. However, the number of catches is still considered high. As an explanation for this situation is the fact that the two orchards are situated at a distance of about 50 meters, and the data in the literature states that European cherry fruit fly can migrate on a distance of over 100 m (Boller, 1969 cited by Stamenković1 et al., 2012).

As in the previous year, this year, the frequency of attacked fruits in chemically treated orchard was approximately 1\% (insecticides used were again from systemic group and induced larval mortality in the population, after emergence). In untreated orchard the frequency of infested fruit ranged between $32 \%$ and $41 \%$.

Tab.4. Number of captures registered in chemically treated orchard, 2014

\begin{tabular}{ccccccccccccc}
\hline Date/Variant & F1 & V1 & F2 & V2 & F3 & V3 & F4 & V4 & F5 & V5 & M & Total \\
\hline 21.05 & 0 & 0 & 0 & 0 & 0 & 0 & 0 & 0 & 0 & 0 & 2 & 2 \\
\hline 30.05 & 0 & 0 & 0 & 0 & 0 & 0 & 0 & 0 & 0 & 0 & 0 & 0 \\
\hline 3.06 & 0 & 0 & 1 & 1 & 2 & 0 & 1 & 0 & 0 & 0 & 0 & 5 \\
\hline 6.06 & 0 & 0 & 0 & 0 & 0 & 0 & 0 & 0 & 0 & 0 & 0 & 0 \\
\hline 10.06 & 12 & 1 & 6 & 1 & 2 & 1 & 3 & 0 & 2 & 3 & 2 & 33 \\
\hline 13.06 & 23 & 6 & 23 & 3 & 23 & 0 & 11 & 5 & 18 & 3 & 7 & 122 \\
\hline 17.06 & 27 & 12 & 11 & 7 & 12 & 1 & 4 & 19 & 7 & 1 & 24 & 125 \\
\hline 20.06 & 26 & 5 & 14 & 4 & 8 & 5 & 9 & 4 & 19 & 4 & 11 & 108 \\
\hline 24.06 & 11 & 2 & 4 & 4 & 4 & 1 & 3 & 1 & 8 & 1 & 4 & 43 \\
\hline 27.06 & 21 & 1 & 8 & 0 & 5 & 4 & 0 & 8 & 9 & 4 & 11 & 71 \\
\hline 1.07 & 6 & 1 & 2 & 0 & 5 & 1 & 2 & 4 & 4 & 2 & 5 & 32 \\
\hline 4.07 & 2 & 1 & 0 & 1 & 1 & 0 & 1 & 1 & 0 & 1 & 1 & 9 \\
\hline 8.07 & 1 & 0 & 0 & 0 & 1 & 0 & 0 & 0 & 0 & 0 & 0 & 2 \\
\hline Total captures & 129 & 29 & 69 & 21 & 62 & 14 & 34 & 42 & 67 & 19 & 66 & 552 \\
\hline No. traps & 5 & 5 & 5 & 5 & 5 & 5 & 5 & 5 & 5 & 5 & 5 & 55 \\
\hline Average/trap & 25.8 & 5.8 & 13.8 & 4.2 & 12.4 & 2.8 & 6.8 & 8.4 & 13.4 & 3.8 & 13.2 & 10.03 \\
\hline
\end{tabular}

Evolution of flight in chemically treated orchard, 2014

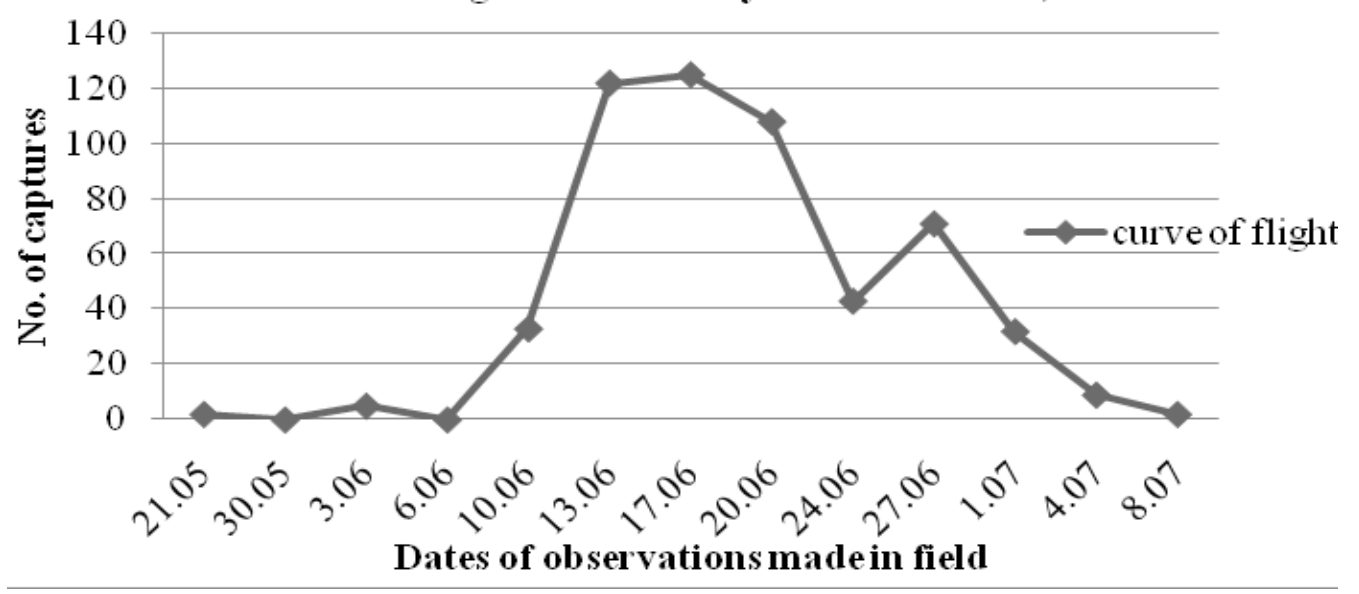

Fig. 4. Flight curve of Rhagoletis cerasi L. species in treated orchard, Cluj, 2014 
The curve flight of Rhagoletis cerasi species, in 2014, in treated orchard, is shown in (Fig. 4.). In this location the adult flight span lasted 51 days (like last year), being with only three days larger than the previous location. It is noted that in the first two weeks, the activity of flight was reduced and it intensified from June 9. In chemically treated orchard the maximum level of catches was recorded during the period June 13 to 17 , with a total of 125 adults captured, but are found throughout this period the number of captures is substantially equal. Also it can be seen that the interval June 13 to 20 were registered 355 capture, representing $64.3 \%$ of total annual catches.

From the data presented, it is found that in untreated orchard, the maximum flight curve in both experimental years was reached faster (with about 2 weeks) due to expositions of plantations (Kovanci and Kovanci, 2006b). Untreated orchard is located on a southern slope and the chemically treated orchard is situated on a flat land with light wane, so the amount of active degrees, necessary for the developement of pupal stage was achived much faster on the southern slope, due to the longer time of exposure to solar radiation.

\section{CONCLUSION}

1 In the Cluj-Napoca area, the emergence of Rhagoletis cerasi L. Adults, takes place in the last decade of May.

2 Adult flight period is spread over a range between 36 and 51 days, depending on the climatic conditions of the year.

3 The most intense period of flight was reached after 2-4 weeks after emergence, this element is influenced by the exposition of cherry plantation.

4. Springs rich in precipitation in the pre-flight period, reduce numerical density of population by inducing a high mortality in pupae with pink eye.

5 Colored pannels can be used successfully in monitoring of numerical density of population and in warning of chemical treatments.

Acknowledgments. This paper was published under the frame of European Social Fund, Human Resources Development Operational Programme 2007-2013, project no.

POSDRU/159/1.5/S/132765.

\section{REFERENCES}

1. Boller E, Prokopy RJ (1976). Bionomics and management of Rhagoletis.Annu. Rev. Entomol., 21:223-246

2. Boller EF (1966). Der Einfluss natürlicher Reduktionsfaktoren auf die Kirschenfliege Rhagoletis cerasi $L$. in der Nordwestschweiz, unter besonderer Berücksichtigung des Puppenstadiums (Doctoral dissertation, Diss. Techn. Wiss. ETH Zürich, Nr. 3815, 0000. Ref.: Bovey, P.; Korref.: Fritzsche, R.).

3. Chireceanu C (2008). Preliminary phenologic model of predicting the adult emergence of cherry fruit fly Rhagoletis cerasi L. (Diptera: Tephritidae) in Baneasa area. Lucrări științifice U.S.A.M.V.B., Seria A, 1: 30-44.

4. Coneru DM (2009). Cercetări privind influența tratamentelor cu insecticide asupra populațiilor de polenizatori ai unor culture agricole. Teză de doctorat, USAMVB Timișoara.

5. Croitoru N, Panuța S, Olesea Ș, Lăcătușu O, Bodescu Mm (2014). Bioecological Aspects Of Fly Or Worm Cherries Rhagolethis Cerasi L. Lucrări Ştiințifice, 57 (2) : 171-174

6. Daniel C (2009) Entomopathogenic fungi as a new strategy to control the European cherry fruit fly Rhagoletis cerasi Loew (Diptera, Tephrtidae). Thesis. Universitat Munchen.

7. Herea ME (2011). Cercetări cu privire la entomofauna dăunătoare și utilă din plantațiile pomicole de cireș și vișin din zona de est a României în urma aplicării diferitelor metode de combatere. Teză de doctorat, U.S.A.M.V. "Ion Ionescu de la Brad" Iași.

8. Kovanci OB, Kovanci B (1999). Monitoring adult population fluctuations of Rhagoletisi cerasi (L.) using yellow sticky traps in Bursa, Turkey. Phytoparasitica, 27 (4): 31

9. Kovanci OB, Kovanci B (2006a). Reduced-risk management of Rhagoletis cerasi flies (host race Prunus) in combination with a preliminary phenological model. Journal of Insect Scienc. 634.

10. Kovanci OB, Kovanci B (2006b). Effect of altitude on seasonal flight activity of Rhagoletis cerasi flies (Diptera: Tephritidae). Bulletin of Entomological Research, 96 :345351.

11. Mincă D, Vîrteiu AM, Petanec D (2011). The Dynamics Of Rhagoletis Cerasi Populations In Climatic Conditions Of Western Romania. Research Journal of Agricultural Science, 43(2): 92-98.

12. Olszak RW, Maciesiak A (2004). Problem of cherry fruit fly (Rhagoletis cerasi) in Poland - flight dynamics and control with some insecticides. Integrated plant protection in stone fruit 27(5): 91 - 96.

13. Ozdem A, Kilincer N (2005). The biology of the European cherry fruit fly [Rhagoletis cerasi L.(Diptera: Tephritidae)]. V International Cherry Symposium 795: 897-904

14. Perju T, Serban M (1996). Eficacitatea curselor colorate in combaterea mustei cireselor (Rhagoletis cerasi L.). Rev. Protectia Plantelor Cluj Napoca, 22(6): 43-46.

15. Stamenkovic S, Milenkovic S, Stamenkovic T, (1996). Population Dynamics Of Rhagoletis Cerasi L. (Diptera, Tephritidae) In Western Serbia. Acta Hort. 410:561-565. 
16. Stamenković S, Pantelija P, Milošević D (2012) Rhagoletis cerasi Loew (Diptera: Tephritidae) -Biological Characteristics, Harmfulness and Control. Pestic. Phytomed. (Belgrade) 27(4): 269-281.
17. Remund U, Boller E (1983). Pièges Visuels Pour la Lutte Biotechnique et Prèvision Nègative de la Mouche de le Cerise, Rhagoletis cerasi L. Fruit Flies of Economic Importance; Cavallo R., Ed. Balkema: Rotterdam, The Netherlands 490-494. 